\title{
Developmental delay referrals and the roles of Fragile $X$ testing and molecular karyotyping: A New Zealand perspective
}

\author{
ELAINE DOHERTY ${ }^{1}$, RACHEL O'CONNOR ${ }^{1}$, ANNA ZHANG ${ }^{1}$, CHRISTINA LIM $^{1}$, JENNIFER M. LOVE ${ }^{1}$, \\ FERN ASHTON $^{1}$, KAREN CLAXTON ${ }^{1}$, NERINE GREGERSEN ${ }^{2}$, \\ ALICE M. GEORGE ${ }^{1}$ and DONALD R. LOVE ${ }^{1,3}$ \\ ${ }^{1}$ Diagnostic Genetics, LabPlus, Auckland City Hospital, Auckland 1148; \\ ${ }^{2}$ Genetic Health Service New Zealand-Northern Hub, Auckland City Hospital; \\ ${ }^{3}$ School of Biological Sciences, University of Auckland, Auckland 1142, New Zealand
}

Received November 13, 2012; Accepted March 12, 2013

DOI: $10.3892 / \mathrm{mmr} .2013 .1386$

\begin{abstract}
Global developmental delay (GDD) affects $\sim 1-3 \%$ of children, many of whom will also have intellectual disability (ID). Fragile $\mathrm{X}$ is the major genetic cause of GDD with mental retardation (MR) in males, accounting for $\sim 20 \%$ of all $\mathrm{X}$-linked MR. As Fragile $\mathrm{X}$ has serious genetic implications, the overwhelming majority of developmental delay (DD) cases referred to our laboratory are concerned with the exclusion of a diagnosis of Fragile X, along with simultaneous karyotype analysis to confirm chromosome aberrations. Critically, molecular laboratories have generally experienced a falling positive detection frequency of Fragile X. In this context, the recent implementation of array-based technology has significantly increased the likelihood of detecting chromosome aberrations that underpin DD. In the current study, we report a Fragile X mutation detection frequency for DD referrals that is comparable with the falling UK detection frequencies. In addition, we find that there is a 9-fold greater likelihood of detecting clinically significant chromosomal aberrations than of detecting a full Fragile X mental retardation 1 (FMRl) gene CGG repeat expansion in cases referred on the basis of DD. We propose a more efficent sequential testing algorithm that involves an initial molecular karyotype, cascading to FMRI gene analysis in the event of a negative result.
\end{abstract}

\section{Introduction}

Global developmental delay (GDD) affects $\sim 1-3 \%$ of children, many of whom will also have an intellectual disability

Correspondence to: Dr Donald R. Love, Diagnostic Genetics, LabPlus, Auckland City Hospital, P.O. Box 110031, Auckland 1148, New Zealand

E-mail: donaldl@adhb.govt.nz

Key words: Fragile X, FMRl gene, karyotype, global developmental delay, molecular karyotype
(ID) (1). The evaluation of children with developmental delay (DD), dysmorphic features and even autistic spectrum disorder has improved as a result of laboratory testing. Many children with DD do not have physical features or medical histories specific enough for a clear diagnosis. Among such patients, laboratory testing may be extremely helpful, and is an integral part of diagnostic evaluation (2). Critically, $\sim 30 \%$ more males than females are affected by GDD/ID, highlighting an underlying gender bias (3).

Chromosomal aberrations are the most common cause of GDD/ID. Historically, the majority of cases referred to a diagnostic laboratory have been analysed using G-banded karyotyping, which detects microscopic genomic abnormalities (>5-10 Mb) including inversions, duplications, deletions, balanced and unbalanced translocations and aneuploidies. G-banded karyotyping is also able to detect levels of mosaic imbalances $>10 \%$.

Implementing array-based technology in place of traditional G-banded karyotyping has increased the frequency of diagnosis among individuals with DD. A recent report documented that in patients with GDD and/or ID, array testing (also known as molecular karyotyping) is diagnostic in $~ 8 \%$ of cases, with G-banded karyotyping accounting for $\sim 4 \%$ (1).

Against the above background, Fragile $\mathrm{X}$ is considered to be the most common inherited disorder to cause DD and accounts for $20 \%$ of all X-linked GDD/ID (4). Consequently, array-based analysis or G-banded karyotyping together with simultaneous Fragile $\mathrm{X}$ testing is routinely requested for cases referred on the basis of GDD/ID.

The documented incidence of Fragile $\mathrm{X}$ among males is 1 in 5161 (5). Classically, affected males have an IQ <70 $(6,7)$, macroorchidism after puberty, macrocephaly, a long face with a prominent forehead and chin, large ears and other connective abnormalities, including hyperextensible finger joints, flat feet, mitral valve prolapse, hypotonia, soft skin and a high arched palate $(8,9)$. The prevalence of Fragile $\mathrm{X}$ syndrome in females is approximately half that found in males. Females generally have milder symptoms, ranging from asymptomatic to severely affected. At least $50 \%$ of affected females have IQ scores in the borderline to ID range. 
The Fragile $\mathrm{X}$ mental retardation 1 (FMRl) gene, which encodes the Fragile $\mathrm{X}$ mental retardation protein (FMRP), carries a polymorphic trinucleotide CGG repeat within the 5 '-untranslated region (UTR). The repeat number varies between 5 and 54 repeats in the normal population. When this polymorphic repeat expands, it is most likely due to slipped-strand mispairing during DNA replication (10).

Repeats of 45-54 fall within the intermediate range. These repeats may be stable or increase from one generation to the next; however, it is very unlikely that they will increase to a full mutation in a single generation. There has been some interest in intermediate repeats and their link with autism/parkinsonism (11-14), but these data require confirmation.

CGG repeats of 55-200 fall within the premutation range. When maternally transmitted, these may expand to a full mutation with different risks determined by the repeat number; 55-59 repeats have a 3.7\% risk of expansion to a full mutation, whereas repeats of 140-200 have a $100 \%$ risk (15). Males and females with premutations may present with Fragile X-associated tremor/ataxia syndrome (FXTAS), usually affecting males $>50$ years of age (16). Females carrying a premutation are at an increased risk ( $20 \%)$ of developing Fragile X-related premature ovarian insufficiency, which usually occurs before 40 years of age (17).

If the number of repeats is $>200$, it leads to hypermethylation of the repeat sequences and the adjacent promoter region of the gene. This induces local chromatin condensation that prevents the binding of transcription factors and the basal transcriptional machinery, which leads to transcriptional silencing of the gene. Critically, FMRP plays a role in mRNA transport and translation and, as a consequence, brain development (18).

Complete analysis of the FMR 1 gene for Fragile $\mathrm{X}$ syndrome requires sizing the expanded CGG repeat in the 5'-UTR region, and determining the methylation status of this locus. Historically, the gold standard of testing has involved PCR amplification and subsequent sizing to determine the CGG repeat number, together with complementary Southern blotting following methylation-sensitive restriction enzyme digestion. This combined approach detects the vast majority of abnormalities within the FMRl gene $(<1 \%$ of individuals with Fragile $\mathrm{X}$ syndrome have a partial or full deletion of the FMRl gene).

Due to the high incidence of DD within the population, testing for Fragile $\mathrm{X}$ represents a significant portion of a molecular laboratory's workload. The UK Genetic Testing Network (UKGTN; http://www.ukgtn.nhs.uk/gtn/Home) has reported that $17 \%$ of all tests requested of a molecular laboratory are for Fragile X. Furthermore, molecular laboratories have experienced a falling positive detection rate. UK data revealed a $3 \%$ positive frequency in 1993 (with only $50 \%$ of tests being for children $<6$ years) compared with a $0.6 \%$ positive frequency in 2008 (19). The UKGTN has implemented specific testing criteria for male and female children to increase the testing efficiency of Fragile X in UK laboratories (http://www.ukgtn. nhs.uk/gtn/What_s_New?contentId=434).

Currently, our own laboratory is experiencing referrals for simultaneous molecular karyotyping and Fragile $\mathrm{X}$ testing. With increasing clinical laboratory workloads we thought it prudent to review our detection frequencies for both Fragile $\mathrm{X}$ and molecular karyotyping in light of the falling detection frequencies for the former experienced in the UK, but with an increase in detection frequencies for the latter. The combination of the two data sets has informed our in-house testing algorithm in achieving efficiency, lowering labour costs and increasing detection frequencies.

\section{Materials and methods}

DNA extraction of blood samples. A total of 2,046 peripheral blood EDTA samples were collected from patients referred for Fragile X testing over 4 years (2008-2011). DNA was extracted using the Gentra ${ }^{\circledR}$ Puregene ${ }^{\circledR}$ Blood kit (Qiagen, Hilden, Germany) according to the manufacturer's instructions. The data reported in the present study involved the confirmation of a clinical diagnosis on the referral to our public hospital laboratory following routine informed consent procedures, and as such are excluded from formal ethics committee approval.

$C G G$ repeat analysis. The analysis of the CGG repeat of the FMRl gene was performed by PCR in a $15-\mu 1$ reaction volume containing $12 \mu \mathrm{l}$ master mix and $60 \mathrm{ng}$ DNA (in $3 \mu \mathrm{l}$ ). The master mix comprised 6.24 $\mu \mathrm{l} \mathrm{Q}$ solution (Qiagen), 1.5 $\mu \mathrm{l} 10 \mathrm{X}$ PCR buffer (Roche, Mannheim, Germany), $1.2 \mu 125 \mathrm{mM} \mathrm{MgCl}_{2}$ solution, $0.96 \mu 1 \mathrm{dNTP}$ mix (3 mM dATP, dTTP, dCTP and $0.75 \mathrm{mM}$ dGTP), $0.275 \mu 1$ 7-deaza-dGTP, $0.3 \mu 1$ dimethylsulf-

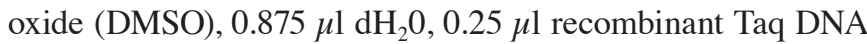
polymerase (Roche), $0.25 \mu \mathrm{l}$ forward primer (AGGCGCTCAG CTCCGTTTCGGTTTCACTTC) and 0.25 $\mu \mathrm{l}$ 6-carboxyfluorescein (6-FAM)-labelled reverse primer (GTGGGCTGCGGG CGCTCGAGG).

One microliter neat and 1:10 dilutions of the PCR samples were subjected to capillary electrophoresis using an 3130xl Genetic Analyser and GeneScan ${ }^{\mathrm{TM}}-600$ LIZ Size Standard (Applied Biosystems, Foster City, CA, USA). All PCR sample batches included one pooled 'process control'. The process control was generated using components B, D, F and $\mathrm{H}$ from the National Institute of Standards and Technology (NIST; Gaithersburg, MD, USA) Fragile X human DNA triplet repeat standard (reference CGG repeat sizes of 30, 51, 73 and 96). Fragment analysis was performed using GeneMapper ${ }^{\circledR}$ v4.0 (Applied Biosystems).

Southern blotting. Southern blotting was undertaken in the event of apparent female homozygotes, males exhibiting apparent null alleles by PCR, samples falling within the premutation range, or referrals with a family history of an FMRl gene CGG repeat expansion. Briefly, $10 \mu \mathrm{g}$ genomic DNA was digested with EcoRI and NruI and electrophoretically separated in a $0.8 \%$ agarose gel containing $1 \mathrm{X}$ Tris-borate-EDTA (TBE) Ultrapure (Life Technologies, Grand Island, NY, USA) at $30 \mathrm{~V}$ for $\sim 20 \mathrm{~h}$. Following DNA transfer, the membranes were hybridized with a digoxigenin (DIG)-labelled FMR1 gene-specific genomic probe, StB12.3. Detection was performed with anti-DIG-alkaline phosphatase (AP) conjugate and the chemiluminescence substrate CSPD.

G-banded karyotype. Cytogenetic G-banded karyotype analysis was requested for 782 of the 2,046 patients. 
Table I. Chromosomal aberrations detected in developmental delay referrals by G-banded karyotype analysis.

\begin{tabular}{|c|c|c|c|}
\hline G-banded karyotype & Syndrome & Gender & CGG repeats \\
\hline $45, X[47] / 46, X, i(X)(q 10)[13]$ & & $\mathrm{F}$ & $24 / 29$ \\
\hline $\begin{array}{l}\text { 46,XX,der(6)t(6;21)(q21;q21.2),der(21)t(6;21)(q21;q21.2)ins (6;18) } \\
(\mathrm{q} 22.2 ; \mathrm{q} 21.3 \mathrm{q} 23) \text { pat }\end{array}$ & & F & $23 / 30$ \\
\hline $46, \mathrm{XX}, \mathrm{del}(2)(\mathrm{q} 24.2 \mathrm{q} 31.1) \mathrm{dn}$ & & $\mathrm{F}$ & $29 / 29$ \\
\hline $46, X Y[19] / 46, X X[17]$ & & $\mathrm{F}$ & $30 / 33$ \\
\hline 46,XY,?del(8)(p23.1p23.1) & & M & 20 \\
\hline $46, X Y, \operatorname{inv}(10)(\mathrm{p} 12.2 \mathrm{q} 11.2)$ & & M & 29 \\
\hline 47,XY,+idic(15)(q13).ish idic(15)(q13)(D15Z1++,SNRPN++) & & M & 29 \\
\hline $47, \mathrm{XY},+\operatorname{mar}[6] / 46, \mathrm{XY}[9] \mathrm{dn}$ & & M & 30 \\
\hline $47, \mathrm{XYY}$ & & M & 36 \\
\hline $47, \mathrm{XYY}$ & & M & 30 \\
\hline $47, \mathrm{XYY}[5] / 46, \mathrm{XY}[59]$ & & M & 36 \\
\hline $47, \mathrm{XXY}$ & Klinefelter & M & 29 \\
\hline $47, \mathrm{XXY}$ & Klinefelter & M & 29 \\
\hline
\end{tabular}

Phytohaemagglutinin-stimulated peripheral blood cultures were synchronized and harvested according to modified methods $(20,21)$ with thymidine added after $48 \mathrm{~h}$ (working solution $30 \mathrm{mg} / \mathrm{ml}$ ) and 2-deoxycytidine (working solution $10 \mu \mathrm{M}$ ) after $64 \mathrm{~h}$ of incubation. Harvesting followed $5-5.5 \mathrm{~h}$ later with colcemid $(10 \mu \mathrm{g} / \mathrm{ml}), 0.4 \% \mathrm{KCl}$ and fixative (3:1 methanol/glacial acetic acid) treatments. Slides were G-banded using trypsin and Giemsa staining.

Molecular karyotype. Genomic DNA was isolated from the peripheral blood of 443 patients using the Gentra Puregene Blood kit (Qiagen) according to the manufacturer's instructions. Genomic DNA $(0.1 \mu \mathrm{g})$ was labelled using the Affymetrix Cytogenetics Reagent kit and labelled DNA was applied to an Affymetrix Cytogenetics $2.7 \mathrm{M}$ array according to the manufacturer's instructions. The array was scanned and the data analysed using the Affymetrix Chromosome Analysis Suite (ChAS; version 1.0, Santa Cruz, CA, USA). Threshold settings of 200 and $400 \mathrm{~kb}$ were used to report deletions and duplications, respectively.

\section{Results}

FMR1 gene testing of cases referred for Fragile X testing. A total of 2,046 samples were referred to our laboratory for Fragile X mutation analysis over a 4-year period (2008-2011). The majority of cases were referred by clinical geneticists and paediatricians on the basis of DD, and many of these were referred for simultaneous karyotype analysis and FMRl gene testing. Our current FMR 1 gene testing strategy involves initial fluorescent PCR followed by Southern blotting if required. Samples that cascade to Southern blotting include apparent homozygous females (which may be true homozygotes or have an amplification product which is beyond the size that our PCR method is able to detect; currently this is $\sim 150$ CGG repeats), null males (indicative of an expansion beyond our PCR limit), premutation samples (which may be mosaic for a full expansion) and familial

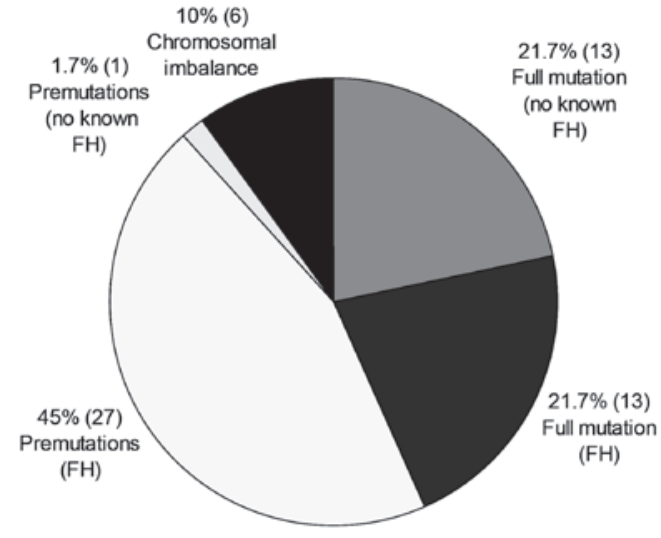

Figure 1. Representation of mutations detected in Fragile X referrals (2008-2011). Sixty abnormalities were identified from a cohort of 2,046 samples referred for Fragile $\mathrm{X}$ testing. Abnormalities were defined as premutations, full mutations or chromosomal imbalances. Fragile X Molecular Testing Guidelines of the American College of Medical Genetics, Standards and Guidelines for Clinical Genetics Laboratories 2006 Edition, (http://www.acmg.net/Pages/ACMG_Activities/stds-2002/fx.htm) were used to define the reference repeat ranges (normal, 5-44; intermediate, 45-54; premutation, 55-200; full mutation, $>200$ repeats). Case numbers are presented in brackets. FH, referrals with a known family history of Fragile X.

cases. Sixty abnormalities were detected (Fig. 1). These included premutations (55-200 CGG repeats), full mutations (>200 CGG repeats) and chromosomal abnormalities (4 with Klinefelter syndrome, 1 with Turner's syndrome and one case of 45,X[14]/46,X,idic(X)(q22.1)[36]). Excluding the chromosomal aberrations, 54 FMR 1 gene abnormalities were identified and of those, $74 \%$ had a family history of Fragile $\mathrm{X}$ syndrome. In total, 13 patients had a CGG repeat expansion $>200$ in the FMRl gene with no known family history (3 females and 10 males), which corresponds to a mutation detection frequency of $0.6 \%$ over the 4 -year period of our study.

G-banded karyotype analysis. Of the 2,046 samples, 782 included a simultaneous G-banded karyotype. Of these, we 
Table II. Chromosomal aberrations detected in developmental delay referrals by molecular karyotype analysis.

\begin{tabular}{|c|c|c|c|}
\hline Molecular karyotype & Region & Gender & CGG repeats \\
\hline arr 3p26.3(2,066,367-2,185,671)x1 & CNTN4 gene (autism spectrum disorder) & M & 29 \\
\hline $\begin{array}{l}\text { arr 3q23(143,303,072-143,567,869) } \\
x 4,16 \mathrm{p} 12.1(21,751,257-22,625,887) \times 1\end{array}$ & Intellectual disability and developmental delay & M & 30 \\
\hline arr 7q11.23(72,362,490-73,781,531)x3 & $\begin{array}{l}\text { Locus associated with } 7 \mathrm{q} 11.23 \\
\text { microduplication syndrome }\end{array}$ & M & 29 \\
\hline arr 8p12p11.1(36,567,009-43,472,531)x3 & $\begin{array}{l}\text { Large duplication not reported in databases } \\
\text { of normal variants }\end{array}$ & $\mathrm{F}$ & $24 / 30$ \\
\hline arr $12 q 14.2 q 14.3(61,455,727-65,269,496) \times 1$ & 12q14 microdeletion syndrome & M & 30 \\
\hline $\begin{array}{l}\text { arr 15q11.2(20,301,313-20,791,706)x3, } \\
15 q 13.2 q 13.3(28,719,170-30,302,219) \times 1\end{array}$ & $15 q 13.3$ microdeletion syndrome & M & 40 \\
\hline $\operatorname{arr} 15 q 11.2 q 13 \cdot 1(20,301,312-26,805,965) \times 1$ & 15q11.2q13.1 deletion PWS/AS & M & 30 \\
\hline arr 15q13.1q13.3(27,016,469-30,482,730)x1 & $15 q 13.3$ microdeletion syndrome & M & 20 \\
\hline arr 15q13.2q13.3(28,698,197-30,564,118)x1 & $15 q 13.3$ microdeletion syndrome & $\mathrm{F}$ & $23 / 30$ \\
\hline arr 15q13.2q13.3(28,698,198-30,710,041)x1 & 15q13.3 microdeletion syndrome & $\mathrm{F}$ & $23 / 30$ \\
\hline $\begin{array}{l}\text { arr } 15 q 13.3(29,793,788-30,302,218) \times 3 \\
16 p 12.1(21,717,216-22,346,279) \times 1\end{array}$ & $\begin{array}{l}\text { 16p12.1 region associated with intellectual } \\
\text { disability and developmental delay }\end{array}$ & M & 31 \\
\hline $\begin{array}{l}\text { arr 16p11.2(29,524,436-30,098,178)x3, } \\
? 16 \mathrm{p} 12.3(18,143,598-18,700,288) \times 1\end{array}$ & 16p11.2 microdeletion/microduplication & M & 29 \\
\hline arr 16p11.2(29,524,436-30,115,034)x4 & Autism susceptibility locus & $\mathrm{F}$ & $29 / 29$ \\
\hline arr 16p11.2(29,559,988-30,098,177)x1 & Autism susceptibility locus & M & 30 \\
\hline arr 16p11.2(29,573,289-30,103,470)x1 & Autism susceptibility locus & M & 30 \\
\hline arr 16p13.11(14,784,599-16,460,694)x1 & Locus associated with developmental disorders & M & 30 \\
\hline arr 17q12(31,460,523-33,671,796)x3 & $\begin{array}{l}\text { Locus associated with mental retardation } \\
\text { and seizures }\end{array}$ & M & 26 \\
\hline arr 22q11.2(17,370,128-20,061,949)x1 & DiGeorge syndrome/VCFS & M & 29 \\
\hline $\begin{array}{l}\text { arr 22q11.21(17,370,127-20,061,948)x 1.nuc } \\
\text { ish(HIRAx1) }\end{array}$ & DiGeorge syndrome/VCFS & M & 29 \\
\hline arr 22q13.31(43,331,656-43,793,482)x3, & 22q13 deletion syndrome & M & 29 \\
\hline 22q13.31q13.33(43,795,931-49,543,031)x1 & (Phelan-McDermid syndrome) & & \\
\hline arr Xp21.3(28,658,360-28,876,705)x0mat & ILIRAPL1 gene & M & 24 \\
\hline $\begin{array}{l}\text { arr Xp22.33p11.1(125,958-58,463,503)x1, } \\
\text { Xq11.1q28(61,934,835-154,888,241)x1 2 }\end{array}$ & Variant Turner syndrome & $\mathrm{F}$ & $24 / 29$ \\
\hline $\begin{array}{l}\text { arr Xp22.33q28(125,959-154,893,779)x2, } \\
\text { Yp11.31q11.23(2,763,232-26,756,229)x1, } \\
\text { 3p24.1p22.3(29,758,852-32,794,893)x1 }\end{array}$ & Klinefelter syndrome & M & 30 \\
\hline $\begin{array}{l}\text { arr Yq11.223q11.23(23,049,037-26,756,231)x } 1 \\
\text { x2 3,2q32.1q33.1(186,331,590-197,832,822) }\end{array}$ & $\begin{array}{l}\text { Partially covers the } 2 \mathrm{q} 33.1 \text { deletion } \\
\text { syndrome region }\end{array}$ & M & 37 \\
\hline
\end{tabular}

CNTN4, contactin-4; PWS, Prader-Willi syndrome; AS, Angelman syndrome; VCFS, velo-cardio-facial syndrome; IL1RAPL1, interleukin 1 receptor accessory protein-like 1 .

detected clinically significant abnormalities in 13 cases not identified by FMRI gene analysis, which represents a detection frequency of $1.7 \%$. Table I summarises the karyotypes together with the concordant negative FMRl gene results. In addition to the abnormalities, we also detected five balanced innocuous translocations (data not shown).

Molecular karyotype analysis. During the last 18 months, our testing criteria for DD cases have been updated to include a molecular karyotype, rather than a G-banded karyotype, in addition to FMRl gene analysis. To date,
443 cases referred for DD have been tested for both CGG repeat expansion in the FMRI gene and chromosomal aberrations using an Affymetrix Cytogenetics array. We detected clinically significant imbalances in 24 cases, which represents a detection frequency of $5.4 \%$. Table II summarizes the karyotypes and the affected loci together with the concordant negative FMRI gene results. In addition to the clinically significant imbalances, we detected 66 cases with imbalances of uncertain significance and 11 cases with long contiguous stretches of homozygosity, which accounts for a further $17 \%$ of all patients (data not shown). 


\section{Discussion}

The overwhelming majority of Fragile $\mathrm{X}$ tests referred to a diagnostic laboratory are to exclude the diagnosis of this condition. Our data reveal a mutation detection frequency comparable with the UK detection levels of $0.6 \%$. The reduced positive detection level has been attributed to a combination of factors including: earlier presentation of children with DD at a level inappropriate for Fragile X; lack of physical features consistent with Fragile $\mathrm{X}$ due to the earlier age of presentation; and an urgency for diagnosis/exclusion of Fragile $\mathrm{X}$ in the parents of younger children (19).

Of 54 cases with an FMR1 gene abnormality, 40 (74\%) had a family history of Fragile X syndrome. Of these, 13 carried a CGG repeat expansion $>200$ [ 2 chorionic villus samples (CVS), and 7 females and 4 males with an age of presentation between 3 months and 34 years]. A further 27 cases were referred with a family history, but carried a premutation (19 female and 8 male samples). Only one male, who was referred based on clinical features of autistic spectrum disorder and DD, carried a premutation with no known family history of Fragile X. It is likely that this expansion is not causative of his clinical features but represents the carrier frequency of this mutation in the general population (1/800; http://www.fragilex.org/ fragile-x-associated-disorders/prevalence/). Additionally, we identified 26 cases with CGG repeats in the FMRI gene that fall within the intermediate range (accounting for $1.3 \%$ of our tested population), which correlates with the reported population frequency of $\sim 2 \%$.

Importantly, there is a 9-fold greater chance of detecting a chromosomal aberration of clinical significance using a molecular karyotype approach than of detecting a full CGG repeat expansion in the FMRI gene in cases with DD [24 of 443 cases $(5.4 \%)$ ]. This mutation detection variance may be higher as we have excluded long contiguous stretches of homozygosity (suggestive of autosomal recessive mutations) and results of unknown clinical significance, which account for a further $17 \%$ of all DD referrals.

Our data support three principal conclusions. Firstly, that Fragile $\mathrm{X}$ testing is an inappropriate first-tier test for DD referrals with no known family history of Fragile X. Secondly, a greater diagnostic yield is provided by a molecular karyotype. Finally, a more efficient testing procedure is to perform molecular karyotyping first, reverting to FMRl gene analysis in the case of a negative molecular karyotype result.

With the emergence of next generation sequencing, many laboratories are now also able to provide whole-exome or $\mathrm{X}$ chromosome exome sequencing for DD referrals, which may prove to be a relevant second-tier test due to its higher mutation detection frequencies, thereby relegating $F M R I$ gene analysis to a third-tier test. We propose that in this new era, FMR1 gene analysis should only be used as a first-line test for cases with a known family history or clinical features strongly suggestive of Fragile X.

\section{References}

1. MichelsonDJ,Shevell MI,SherrEH,etal: Evidence report: genetic and metabolic testing on children with global developmental delay: report of the Quality Standards Subcommittee of the American Academy of Neurology and the Practice Committee of the Child Neurology Society. Neurology 77: 1629-1635, 2011.

2. Miller DT, Shen Y, Harris DJ, et al: Genetic testing for developmental delay: keep searching for an answer. Clin Chem 55: 827-832, 2009.

3. Raymond FL: X linked mental retardation: a clinical guide. J Med Genet 43: 193-200, 2006.

4. Fishburn J, Turner G, Daniel A, et al: The diagnosis and frequency of X-linked conditions in a cohort of moderately retarded males with affected brothers. Am J Med Genet 14: 713-724, 1983.

5. Coffee B, Keith K, Albizua I, et al: Incidence of fragile X syndrome by newborn screening for methylated FMR1 DNA. Am J Hum Genet 85: 503-514, 2009.

6. Loesch DZ, Huggins RM and Hagerman RJ: Phenotypic variation and FMRP levels in fragile X. Ment Retard Dev Disabil Res Rev 10: 31-41, 2004.

7. Rousseau F, Heitz D, Tarleton J, et al: A multicenter study on genotype-phenotype correlations in the fragile $\mathrm{X}$ syndrome, using direct diagnosis with probe StB12.3: the first 2,253 cases. Am J Hum Genet 55: 225-237, 1994.

8. Chudley $A E$ and Hagerman RJ: Fragile $X$ syndrome. J Pediatr 110: 821-831, 1987.

9. Lachiewicz AM and Dawson DV: Do young boys with Fragile $X$ syndrome have macroorchidism? Pediatrics 93: 992-995, 1994.

10. Kunkel TA: Nucleotide repeats. Slippery DNA and diseases. Nature 365: 207-208, 1993.

11. Deng H, Le W and Jankovic J: Premutation alleles associated with Parkinson disease and essential tremor. JAMA 292: 1685-1686, 2004.

12. Loesch DZ, Khaniani MS, Slater HR, et al: Small CGG repeat expansion alleles of FMR1 gene are associated with parkinsonism. Clin Genet 76: 471-476, 2009.

13. Cilia R, Kraff J, Canesi M, et al: Screening for the presence of FMR1 premutation alleles in women with parkinsonism. Arch Neurol 66: 244-249, 2009.

14. Kraff J, Tang HT, Cilia R, et al: Screen for excess FMR1 premutation alleles among males with parkinsonism. Arch Neurol 64: 1002-1006, 2007.

15. Nolin SL, Brown WT, Glicksman A, et al: Expansion of the fragile X CGG repeat in females with premutation or intermediate alleles. Am J Hum Genet 72: 454-464, 2003.

16. Rousseau F, Labelle Y, Bussieres J, et al: The fragile $\mathrm{x}$ mental retardation syndrome 20 years after the FMR1 gene discovery: an expanding universe of knowledge. Clin Biochem Rev 32: 135-162, 2011.

17. Schwartz CE, Dean J, Howard-Peebles PN, et al: Obstetrical and gynecological complications in fragile X carriers: a multicenter study. Am J Med Genet 51: 400-402, 1994.

18. Lu R, Wang H, Liang Z, et al: The fragile $\mathrm{X}$ protein controls microtubule-associated protein $1 \mathrm{~B}$ translation and microtubule stability in brain neuron development. Proc Natl Acad Sci USA 101: 15201-15206, 2004.

19. LuntP:Testing criteriaforfragileXsyndrome:reportof theoutcome from the UKGTN Fragile X Workshop. http://www.ukgtn.nhs. uk/gtn/digitalAssets/0/971_UKGTNFraXworkshopFINAL2010. pdf. Accessed November, 2012.

20. Gallo JH, Ordonez JV, Brown GE and Testa JR: Synchronization of human leukemic cells: relevance for high-resolution chromosome banding. Hum Genet 66: 220-224, 1984.

21. Moorhead PS, Nowell PC, Mellman WJ, et al: Chromosome preparations of leukocytes cultured from human peripheral blood. Exp Cell Res 20: 613-616, 1960. 